\title{
Computerized documentation and community health nursing students
}

\author{
Nadine M. Aktan, J anet Tracy, Connie Bareford \\ Department of Nursing, William Paterson University, New Jersey, USA \\ Correspondence: Assistant Professor Nadine M. Aktan, Address: 300 Pompton Road, Wayne, NJ 07470. Telephone: \\ (973) 720-2527. Email: aktann@wpunj.edu \\ Received: June 28, 2011 \\ DOI : 10.5430/jnep.v1n1p25 \\ Published: December 1, 2011 \\ Accepted: October 18, 2011
}

\begin{abstract}
Background/Objective: Proficiency in computerized documentation systems is an essential element of most areas of nursing practice today. Community health is one example of an area of nursing practice where computerized documentation systems help in the provision of high quality care. Nursing students must learn the basic principles of and begin to participate in the practices of computerized nursing documentation. It is, therefore, the responsibility of nursing faculty to promote student involvement in this important process.

Methods: Two different faculty experiences with students participating in computerized nursing documentation were described using different electronic systems, a notebook computer system and a Personal Digital Assistant (PDA) system.

Results/Conclusions: After reviewing the results of this descriptive experience, it is recommended that before students participate in computerized documentation, they receive written instructions. Sample charts, practice under direct faculty and staff guidance, and standardizing the learning experience are imperative. Educating the student in a technological environment is no longer optional for nurse faculty as the accurate documentation, transmission and management of data assures that the best practices are maintained, the proper billing of visits can be ensured, and the communication between the nursing student and community health nurses, as well as all members of the multi-disciplinary team is fostered.
\end{abstract}

\section{Key words}

Computerized documentation, Community health, Nursing students, Clinical teaching

\section{I ntroduction}

Accurate documentation is an essential element of all areas of nursing practice. Home care nursing is one specialty where clear, concise, thorough record keeping is crucial. Community health nurses must be proficient in the principles of the proper documentation of nursing activities. Community nurses are often the only health care professional the patient encounters and documentation at the point of care is encouraged so that important data is not missed or forgotten. Therefore, this process is essential and nursing students must be instructed on and have the opportunity to engage in computerized charting during their community health rotation.

Today, nurses are required to chart via computerized documentation systems. Nursing faculty need to foster student involvement into and preparedness in the practice of computerized charting in order to properly prepare the nurses of 
tomorrow. The existing literature does not guide the nurse faculty in the mechanics and philosophy supporting the importance of this essential process. These authors have found that more recent inquiry into student and faculty involvement in computerized documentation systems in community health is needed.

According to the Commission on Collegiate Nursing Education's (CCNE) Standards for Accreditation of Baccalaureate and Graduate Nursing Programs, accreditation is a nongovernmental process conducted by representatives of postsecondary institutions and professional groups. Accreditation focuses on the quality of institutions of higher and professional education and on the quality of educational programs within institutions. Professional accrediting agencies assess the extent to which programs achieve their stated mission, goals, and expected outcomes and consideration of the program's mission, goals, and expected outcomes is of importance to the accrediting agency in determining the quality of the program and the educational preparation of members of the profession or occupation [1].

As an accrediting agency, CCNE recognizes that advancements in technology have enabled programs to facilitate the educational process in ways that may complement or supplant traditional pedagogical methods. CCNE encourages the introduction and use of innovative teaching and learning strategies in the curriculum and looks to the programs that it accredits to make available this technology for the improvement and enhancement of student learning [1].

Specifically, the CCNE accreditation requirements speak to Program Quality: Curriculum and Teaching-Learning Practices. One of the key elements is that the curriculum is developed to reflect professional nursing standards and guidelines. Student involvement in computerized charting systems fosters competency of this professional nursing standard. Information literacy is crucial to the future of nursing and the improvement of cost-effectiveness and safety depend on information management and technology, with electronic medical records being just one example of these processes [1].

Additionally, one of the essentials identified for baccalaureate education is the ability of the graduate to utilize the skills and knowledge in information management and technology that will result in quality patient care. This document speaks to information management and the application of patient care technology and concludes that graduates of baccalaureate programs must have competence in using both. These factors contribute to the renewed commitment nursing faculty must make as we strive to adequately prepare our students for the roles they will fulfill in the health care system today, as well as the one they will continue to function successfully in tomorrow [2].

The American Nurses Association (ANA) has set forth a number of position statements on electronic health records (EHRs). It is the ANA position that [3]:

The public has a right to expect that health data and healthcare information will be centered on patient safety and improved outcomes throughout all segments of the healthcare system and the data and information will be accurately and efficiently collected, recorded, protected, stored, utilized, analyzed, and reported. Principles of privacy, confidentiality, and security cannot be compromised as the industry creates and implements interoperable and integrated healthcare information technology systems and solutions to convert from paper-based media for documentation and healthcare records to the newer format of electronic health records (EHRs), including individual personal health record (PHR) products.

Further, the ANA states that the organization [3]:

Strongly supports efforts to further refine the concept and requirements of the patient-centric EHR, including the creation of standards-based electronic health records and supporting infrastructures that promote efficient and effective inter-professional and patient communications and decision-making wherever care is provided. Similar attention must address the secondary uses of data and information to generate knowledge that leads to improved and effective decision tools. All stakeholders, including nurses and patients, must be integral participants in the 
design, development, implementation, and evaluation phases of the electronic health record. This effort requires the attention and action of nurses, the professional and specialty nursing organizations, and the nursing profession to ensure the EHRs are designed to facilitate and support critical thinking and decision making, such as in the nursing process, and the associated documentation activities. It is ANA's position that the registered nurse must also be involved in the product selection, design, development, implementation, evaluation and improvement of information systems and electronic patient care devices used in patient care settings .

In reviewing these policy statements by our nursing professional organization the importance of nursing student participation of computerized documentation practices has become even more paramount.

A variety of factors make it difficult to teach clinical documentation to nursing students in the classroom. Some of these include, but are not limited to: cost, time, and system compatibility constraints and it is even more urgent for newer nurses to master basic clinical documentation technologies since the clinical environment is increasingly more automated [4]. Therefore, the responsibility of the nursing faculty is to incorporate computerized charting documentation principles into clinical curriculum in all areas including community health.

The existing research on computerized charting and nursing rarely discusses students. One current published study, sought to test an inexpensive software application designed to assist students in learning to document nursing care in the laboratory [4]. The researchers implemented a data-based system using Windows and Microsoft Access mounted on a lap top at a bedside in the laboratory. The result was that students were more positive about the systems, but were not necessarily more efficient. This study also demonstrated that nursing students could efficiently learn how to use an electronic documentation system with a standard terminology to improve patient care plans.

An additional study, which included eighteen senior nursing students, critically examined an existing computerized documentation system [5]. The authors believed that nursing students would be the ideal candidates to provide feedback on a computerized charting system since they believed them to possess higher technology awareness and were not tied to a previous system. They also felt that students were accustomed to learning new information daily and used computers in their educational programs. The primary objective of this study was to elicit critiques and to determine how to make the learning process easier. One result of this study was that the nursing students varied in the length of time necessary to become competent with the computerized charting system. Also, they were not intimidated by the use of the computer program. The researchers recommended that faculty prepare students more thoroughly by incorporating computerized instruction in the classroom and preparing a handout with typical troubleshooting for hardware and software problems [5].

Overall, computerized charting in nursing is a well-documented process. However, its use in the community health setting has not been recently presented in the literature. Student use of computers in home care is limited. Therefore, the use of paper charting for students which then requires the transcription of nursing notes to the patient record is a time-consuming process that does not properly prepare the student to acquire this essential nursing skill.

\section{Methods}

Two separate home care agencies using different electronic systems, a notebook computer system and a Personal Digital Assistant (PDA) system, were used by one university program where nursing students charted during clinical rotations. In comparing these two agencies, there were many similarities. Before each visit, students received a printout of the last home visit including patient assessment, clinical notes and medication list. Students took their electronics with them during the home visit and were encouraged to record on the device. Most students recorded the assessment data in the home, but waited to document the clinical note and plan for the next visit at the agency. 
At the end of the visit, students returned to the agency and finished their electronic input. The nursing instructor then recommended corrections or additions, and asked the student questions about the patient's response to care. It was noted that several of the students who quickly learned the system were able to also assist their peers.

Upon completion of each student/patient interaction, the instructor provided her electronic 'signature' to the documentation by means of an annotation indicating that the faculty had read and approved the notes. Additionally, both agencies were certain to only load the data from the specific patient which was assigned to the student. This assured the agency of privacy of data and decreased the opportunity for breach of confidentiality.

There were also differences identified in using the two devices_-PDA's and notebooks. In the clinical experience in which the PDA's were used, two clinical groups of students rotated to the agency over two semesters. The total training time for students ranged from two half days in the pilot program to one half day after the second semester of full implementation. The agency was responsible for the initial uploading of patients, the checking of billing codes, the transmitting of data onto the server for PDA use and the cleaning of the devices of data at the end of the day.

Once set up on the server the patient data was downloaded to the PDA by the student, and the nursing faculty had access to the patient information system at the agency via laptop. With the student having her PDA in hand and the faculty using the laptop, all pertinent information for this patient could be accessed in order to plan for the home visit. The instructor had a wide range of available data, including data from any home visit made to the patient, from nursing, physical therapy, speech therapy and social work. All orders and certification information was also available. This enabled the instructor to guide the student through the case management process.

In the clinical experience where notebook computers were used, two clinical groups were assigned over one semester. Two half days of orientation allowed students to take a portion of the nurse computer course and participate in a "mock up” patient chart. The second day provided another opportunity for questions and practice with the "laboratory patient." This unique experience provided an opportunity for students to document with agency staff support prior to the expectation of charting on actual patients fostering comfort and competence for the subsequent computerized charting process.

\section{Results}

Both agencies had their nursing staff upload patients, check the billing codes, transmit the data onto the server, clean the computers of data and redo the visits for the next day. This facilitated the use of only 10 computers for the 40 students rotating through the agency in one week, an effective cost-maintaining strategy. This support staff from the agency estimated that 12-15 hours per week were needed to provide all of the nursing students with the necessary computers.

Although the paper charting system also required a great deal of agency time, this role was previously accomplished by secretaries and clerks. The computer system was managed by a nurse and therefore calculated as a higher level of expense. After a one semester pilot program with the two clinical groups, this agency discontinued the use of the notebooks by students citing the time-intensity, the lack of available staff to support the process, and the need to distribute the notebooks to their own staff. After four semesters, the agency using PDA's discontinued their use because of software changes in the computer network.

Both groups of nursing students reported being enthusiastic about the electronic documentation and adapted easily and willingly to its use. They found that the 'routine home visit' flow sheets were a cue for them to gather pertinent data and to complete a thorough assessment. Furthermore, students found that the drop-down menus were helpful in selecting a focus for the visit and each new field structured their assessments and patient findings. The students were guided through screens 
for reminders to chart wound sizes, assess for the presence of pain, weights of patients with CHF, and blood sugar histories on diabetic clients.

For the neophyte student preparing for a home visit, this was a welcome reminder of the data which should be gathered during the visit and assisted in learning protocols as well as standardizing the visit. The ability to revise the clinical notes in progress was also a plus. Students became adept at using the electronic methods. Portable keyboards were available and students found that while the documentation may take longer than a paper note, the electronic documentation 'really meant something' because everyone at the agency could access the student's home visit. "We were part of the record that everyone could see.” This engendered a sense of self confidence and trust which increased their feelings of belonging to the team—an important element in the mentoring of nursing students by professional nurses.

\section{Discussion}

Agency staff from both of the described agencies was willing and able to train and assist. The nurse assigned to the students for their technology competencies expressed awe at their speed in learning and retention of knowledge in spite of only using the system once per week, believing students learned more quickly than staff-many of whom had resisted because it was a change from their previous way. She also expressed an overall appreciation of the students' service to the agency and positivity about the process as she worked more closely with them than in previous semesters.

Since the full-time nurses were using the electronics, the inclusion of nursing students was seen as a natural development by agency nurses and faculty alike. Prior to this, the student's paper notes were inaccessible to anyone unless they were physically acquisitioned from medical records - a time-consuming, inconvenient, and unlikely process. Overall with the use of electronic documentation, everyone has access to the same information in a timely manner.

\section{I mplications}

The transition to computerized charting practices may present challenges, both for the nursing instructor and for the nursing student. Yet there are many benefits to the successful implementation of this process. These include the clinician, student, faculty, and agency administrators working together to improve efficiency, capturing the current assessment of the patient, and decreasing the amount of paperwork to be completed after the visit. More specifically, when joint visits between the clinician and the student take place, the nurse can delegate portions of the documentation directly to the student and both will benefit from this experience. In cases where students make independent home visits under the supervision of their instructor, all members of the home care team would save time in having student visit information easily accessible when needed by direct charting into the computer.

There are other positive aspects to these practices as well. It is well known that nurses spend a great deal of their time doing paperwork. If computerized charting systems are designed and correctly implemented, this gives agencies the ability to reduce costs and improve care. Therefore, when the student is permitted access to chart in the computerized patient record, all parties involved will benefit. With these critical factors becoming more apparent, the nurses of tomorrow need to be better prepared to tackle our ever-changing, technologically-driven health care system.

\section{Limitations}

There are also a few drawbacks to student involvement with computerized charting in the community health setting. First and foremost, the transition from paper to computerized charting is not automatic: the presentation of computerized screens is not necessarily intuitive, nor sequenced similarly to paper charting [6]. As with paper charting, at times there were delays in waiting for the instructor's feedback and eventual overall approval of the notes charted. Another concern 
identified is that some clinicians have initially found these systems difficult to use. For example, some systems have drop-down menus while others allow self-composition of notes-most now offer a combination of these types of documentation modalities. However, as with any system, time and patience from all parties involved will foster student success.

One added problem which may be encountered and needs to be addressed is how the general nature of the student experience can be challenged. Students are in the process of role adaptation-facing the multitude of challenges presented by the community health setting, particularly a higher level of autonomy. Learning a detailed computerized system may interfere with their mastery of basic community health skills. This can also interfere with the student's ability to adequately engage the patient and the family. Yet when the student, instructor, clinician, and management work together, the mutual learning environment, as well as the overall student experience, can be positive.

This paper presents an essential topic for additional exploration in the literature due to our current health care environment where nursing students are a potential source of agency recruitment. The literature is sparse in addressing students' use of electronic charting in home care. Yet college-aged students are using technology constantly and recruiters must be mindful that students in their clinical rotations are "ripe" for nursing positions upon graduation. Agencies must remain invested in the exceptional educational experiences of nursing students today as it is, in fact, these individuals that they will be recruiting tomorrow.

\section{Conclusion}

In summary, although training time may be lengthy, it is imperative that students become familiar with the language used in standardized computerized charting in all settings—-with community health providing just one descriptive example. With nursing students having adequate knowledge of and participating in these electronic systems, proper billing of visits can be ensured, as well as improved communication with community health nurses and all members of the multi-disciplinary team be fostered.

If implementing student participation in computerized documentation systems, it is recommended to nursing faculty that they receive written instructions on the first day with step-by-step clarity. Sample charts and practice under direct faculty and agency nursing and/or administrative staff guidance are imperative before, during, and after actual client visits take place. By standardizing the entire student learning experience, routine protocols can be reviewed both by faculty and by agency nurses/administrative personnel and group questions can be addressed rather than the time consuming one-to-one questions. Overall, as the learning process progresses, the support needed to use the system by the nursing student diminishes. Implementing the information technology into student learning requires a commitment on the part of the faculty and the agency; however, educating the student in a technological environment is hardly an option as the accurate documentation, transmission and management of data assure that best practices are maintained.

In preparing new baccalaureate nursing graduates for the future, these skills are necessary whether in acute care agencies or out in the community. To expose students to this opportunity as part of the learning experience includes them in the cutting edge of client care where they are expected to function as a new graduate. Incorporating these practices into nursing curriculum is no longer optional for baccalaureate nursing programs. In order to prepare our graduates to maintain the highest standards of the profession, these practices are now an expectation.

\section{References}

[1] American Association of Collages of Nursing [Internet]. Available from: http://www.aacn.nche.edu/Accreditation/standards.htm

[2] American Association of Collages of Nursing. The Essentials of Baccalaureate Education for Professional Nursing Practice

[Internet]. 2008. Available from: http://www.aacn.nche.edu/Education/pdf/BaccEssentials08.pdf 
[3] The American Nurses Association. Health care and Policy [Internet]. Available from: http://www.nursingworld.org/MainMenuCategories/HealthcareandPolicyIssues/ANAPositionStatements/practice.aspx

[4] Feeg V, Saba V, Feeg A. Testing a bedside personal computer clinical care classification system for nursing students using Microsoft Access. Computers, Informatics, Nursing. 2008; 26: 339-349. PMid:19047883 http://dx.doi.org/10.1097/01.NCN.0000336465.17811.3c

[5] Schneiderman J, Bullough-Latsch J, Dolson M. Nursing students and computerized charting: Lessons learned. Nurse Educator. 2000; 25: 206. PMid:16646190 http://dx.doi.org/10.1097/00006223-200009000-00003

[6] Turpin P. Transitioning from paper to computerized documentation. Gastroenterology Nursing. 2005; 28: 61-2. PMid:15738738 http://dx.doi.org/10.1097/00001610-200501000-00016 